\title{
MicroRNA biogenesis and regulation of bone remodeling
}

Kristina Kapinas ${ }^{1}$ and Anne M Delany ${ }^{* 2}$

\begin{abstract}
MicroRNAs (miRNAs) are key post-transcriptional regulators of gene expression. This review will highlight our current understanding of miRNA biogenesis and mechanisms of action, and will summarize recent work on the role of miRNAs, including the miR-29 family, in bone remodeling. These studies represent the first steps in demonstrating the importance of miRNAs in the control of osteoblast and osteoclast differentiation and function. An in-depth understanding of the roles of these regulatory RNAs in the skeleton will be critical for the development of new therapeutics aimed at treating bone loss and perhaps facilitating fracture repair.
\end{abstract}

\section{Introduction}

Transcription factors, RNA binding proteins, and microRNAs (miRNAs) are among the factors that must act coordinately to control gene expression networks important for cellular function [1]. Following transcription, mRNAs are subject to the processes of splicing, nuclear export, trafficking, and polyadenylation, followed by translation initiation and elongation. Each of these processes represents a point at which expression can be regulated, allowing for fine-tuning in response to changing environmental conditions. miRNAs are short (approximately 21-nucleotide) non-coding RNAs that regulate transcript localization, polyadenylation, and translation. miRNAs are direct negative regulators of gene expression that bind to specific sequences within a target mRNA $[2,3]$. miRNAs were discovered as a result of studies aimed at identifying genes that mediate developmental transitions in Caenorhabditis elegans [4,5]. Recent years have seen significant advances in the miRNA field, including the

*Correspondence: adelany@uchc.edu

${ }^{2}$ Center for Molecular Medicine, University of Connecticut Health Center,

263 Farmingtion Ave, Farmington, CT 06030, USA

Full list of author information is available at the end of the article characterization of the miRNA biogenesis pathway, identification of the mechanisms by which miRNAs regulate gene expression, and an appreciation of how families of miRNAs can regulate cellular processes and contribute to disease phenotypes.

The goal of this review is to highlight our current understanding of miRNA biogenesis and mechanisms of action, and to summarize recent studies on the role of miRNAs in bone remodeling.

\section{miRNA biogenesis}

The miRNA biogenesis pathway has several steps: transcription, pri-miRNA processing, transport to the cytoplasm, precursor miRNA (pre-miRNA) processing, strand selection, transcript targeting, and transcript fate (Figure 1). This rigorous, multistep processing pathway helps ensure that only RNAs with the correct structures and sequences are able to regulate gene expression.

miRNA genes are found on every chromosome in humans, except for the Y chromosome. Like the promoters of protein-coding genes, miRNA promoters are regulated by epigenetics and by transcription factors. miRNA genes are transcribed by RNA polymerase II or III, from independent miRNA genes, or from the introns of protein-coding or non-protein-coding genes [6,7] (Figure 2). The initial product of miRNA gene transcription is the primary transcript (pri-miRNA), which may be several thousand nucleotides long. Multiple miRNAs may be co-transcribed in a single pri-miRNA. The entire pri-miRNA is capped and polyadenylated, like mRNA transcripts. Tandem transcription of several miRNAs, possibly along with protein-coding genes, allows the genes to be expressed together. These coexpressed genes may interact within the same pathway or through crosstalk between pathways. The co-expression of miRNA and protein-coding genes may also function to ensure negative feedback on the protein-coding gene to prevent its over-expression [8].

In mammals, the pri-miRNA is processed within the nucleus by the Drosha-DiGeorge syndrome critical region gene 8 (DGCR8) complex (Figure 1, in nucleus). Drosha is an RNase III-type endonuclease, and DGCR8 is thought to recruit and bind the transcript [9]. The 


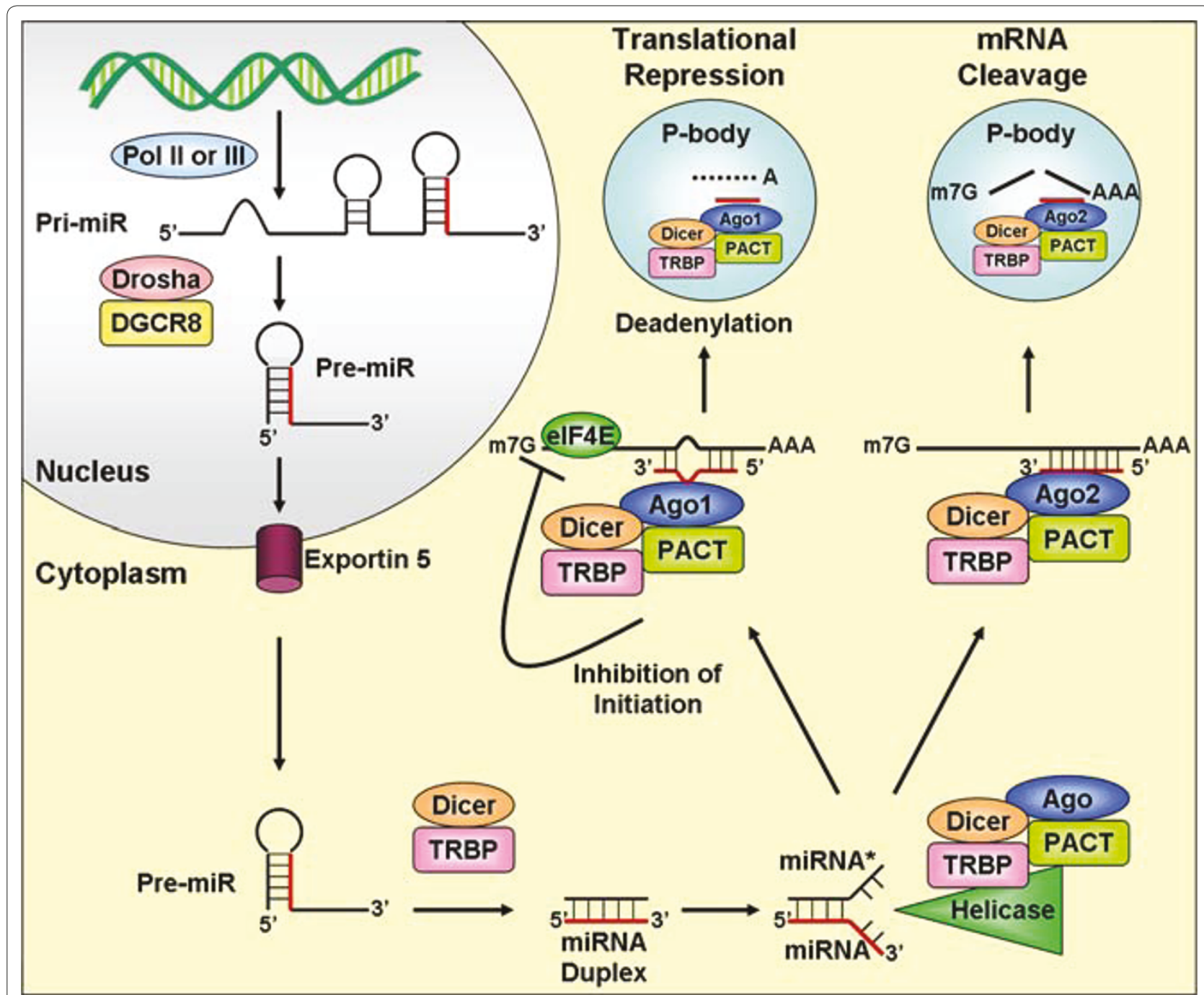

Figure 1. MicroRNA biogenesis pathway. miRNAs are transcribed by RNA polymerase (Pol) II or III into primary (pri)-miRNAs, which are processed by Drosha/DGCR8 (DiGeorge syndrome critical region gene 8) into precursor (pre)-miRNAs. The mature miRNA strand is highlighted in red. The premiRNA is transported from the nucleus into the cytoplasm by Exportin 5, where it is then processed by Dicer/TRBP (Dicer-TAR RNA binding protein) into a miRNA duplex. The duplex is unwound by a helicase and the mature strand (red) is incorporated into the RNA-induced silencing complex (RISC). Depending on miRNA complementarity to a target mRNA, the RISC mediates down-regulation of gene expression by either translational repression or mRNA degradation. Ago, Argonaute; PACT, protein activator of PKR; P-body, processing body.

sequences preceding the $5^{\prime}$ end and trailing the $3^{\prime}$ end of the pri-miRNA form an imperfect stem that is recognized by DGCR8, which allows Drosha to cleave approximately 11 bp away $[9,10]$. Pri-miRNAs are cleaved into precursor miRNAs (pre-miRNA), which are approximately 60- to 100-nucleotide hairpins. The pre-miRNA is then transported from the nucleus into the cytoplasm by Exportin 5 and Ran-GTP [11]. Exempted from this processing pathway are short introns containing miRNA precursors, called 'mirtrons' (Figure 2). Spliced and debranched mirtrons are able to bypass processing by Drosha, and access the canonical miRNA processing pathway following nuclear export [12].
Pre-miRNAs are further processed by the Dicer-TAR RNA binding protein (TRBP) complex [13] (Figure 1, in cytoplasm). Dicer is another RNase III-type endonuclease, and TRBP is thought to recruit and bind the pre-miRNA, and to stabilize the Dicer-RNA interaction. There are several requirements for duplex recognition and cleavage by Dicer [14]. For example, only miRNA duplexes with central mismatches will form an efficient complex with Dicer/Ago1 (Argonaute). Mismatches in the seed region or 3' end promote unwinding of the duplex, whereas the terminal loop may promote enzyme turnover $[14,15]$. Dicer cleavage yields an approximately 21-nucleotide miRNA duplex, which is incorporated into 


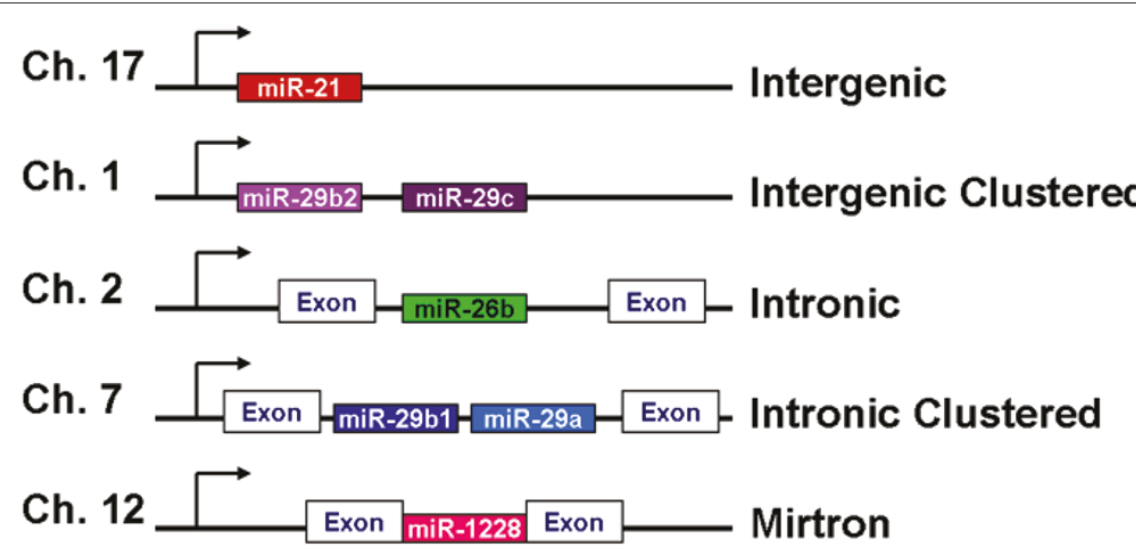

Figure 2. Genomic orgranization of microRNA genes. miRNA genes can be intergenic (alone or clustered), in the intron of non-coding RNA or protein-coding genes (alone or clustered), or can be mirtrons (part of a short intron of another gene).

the RNA-induced silencing complex (RISC). The RISC includes Dicer, TRBP, PACT (protein activator of PKR), and one of four Ago proteins [16]. The miRNA duplex is unwound by helicases into two single strands, the mature guide strand (miRNA; red strand in Figure 1) and the complementary passenger strand (miRNA*) [14]. Guide strand selection is dependent on the first 5 ' nucleotides and which Ago protein is present in the RISC [17].

The miRNA* is typically degraded by the RISC, although some miRNAs* are thought to negatively regulate gene expression, like a mature miRNA. It is not known why some miRNAs* are functional. One hypothesis is that the strands could be used differently in response to extracellular or intracellular cues, to regulate a more diverse set of protein-coding genes as needed, or strand selection could be tissue specific [18]. Strand selection also limits regulation by miRNAs* generated from highly expressed precursors.

While the mechanisms regulating miRNA biogenesis have been well studied, the regulation of miRNA stability, particularly in vertebrates, is not well understood. It is known that mature miRNA abundance is sensitive to Ago protein levels, suggesting that association with Ago can protect miRNAs from degradation [19]. Although most miRNAs appear to be stable, they do possess differential stability. One miRNA, miR-122, was recently shown to be stabilized by the addition of a single adenosine to its 3' end through the activity of the cytoplasmic poly(A) polymerase GLD-2. In contrast, uracils at positions 9 to 11 are important for the short half-life of miR-29b [15]. miR-382 also has a short half-life, due to sequence elements in the 3' end of the miRNA. The exosome 3'-5' exonuclease complex was shown to be important for miR-382 decay [20]. Discovery and characterization of cis-and trans-acting factors regulating miRNA stability is a topic of intense study.

\section{miRNA functions}

Once the RISC contains the guide strand, it delivers the miRNA to the target mRNA, where base pairing occurs. Most miRNA binding sites lie within the 3' UTR, although there are some reports of miRNAs binding in the 5' UTR and coding region of mRNAs [21,22]. There appears to be a biological basis for the preferential interaction of miRNAs with the 3' UTR. Data suggest that miRNA binding sites within the coding region of a transcript are less effective at mediating translational repression. This is likely due to the ability of ribosomal complexes to override and inhibit the interaction of the miRNA-RISC with the potential binding site(s) [23]. Similarly, relatively few functional miRNA binding sites are located in the 5' UTR of a transcript. The scanning activity of the ribosome may impair the interaction of the miRNA-RISC with the 5' UTR, suggesting there would be inefficient inhibition of gene expression. Although the general location of a miRNA binding site within the transcript helps define the degree of repression mediated by miRNAs, other factors contribute to efficacy. These factors include the sequence context of the miRNA binding site, the number of target sites within the mRNA, the local RNA structure, and distance between target sites [24-27].

The degree of base pairing between the miRNA and its target determines the fate of the transcript. Of particular importance is the interaction between the 'seed' region of the miRNA (nucleotides 2 to 8 ) and the 3 ' end of the transcript's miRNA binding site. The seed region nucleates miRNA binding. If there is perfect binding between the miRNA and target, the mRNA target is cleaved by the endonuclease Ago2, possibly in RNA processing bodies (P-bodies) [28,29]. However, most metazoan miRNAs bind imperfectly to their targets, triggering translational repression. In such cases of imperfect miRNA-mRNA 
binding, there is frequently a bulge between the miRNA and its target, between the 9th and the 11th nucleotide of the miRNA, which induces translational suppression [30].

For a majority of mRNAs, translation initiation occurs when the 5 '-cap $\mathrm{m} 7 \mathrm{GpppN}$ is recognized by eIF4E, a component of the eukaryotic translation initiation factor eIF. This complex also includes eIF4G, which interacts with eIF3, to recruit the $40 \mathrm{~S}$ ribosomal subunit, and with polyadenylate-binding protein 1 (PABP1). The interaction of eIF4G with both eIF4E and PABP1 physically brings the 5' and 3' ends of the mRNA close together, stimulating translation initiation by increasing affinity of eIF4E for the 5'-cap. Trans-acting factors that bind the 3' UTR inhibit translation by recruiting proteins that block the eIF4E-eIF4G interaction or that bind to the 5'-cap, preventing assembly of the $40 \mathrm{~S}$ ribosome initiation complex [31]. Several studies have shown this to be the case for components of the RISC, specifically Ago proteins [32,33]. The central domain of the Ago protein family has some sequence homology to the eIF4E cap-binding domain. Mutation of these residues in Ago proteins abolishes translational repression of $\mathrm{m} 7 \mathrm{G}$ mRNAs, suggesting that Agos can compete with eIF4E to inhibit translation [34].

miRNAs can also repress translation at post-initiation steps. miRNA-RISC can bind to actively translating mRNAs, reducing translational elongation and/or enhancing termination, concomitant with a reduction in ribosomal initiation and nascent peptide destabilization. As a component of the RISC, Ago proteins 1, 3, and 4 are thought to mediate post-initiation inhibition $[35,36]$.

Initial studies of miRNA targets suggested that only the protein levels of regulated targets were decreased, whereas the levels of target mRNAs themselves were not affected. However, altering miRNA expression in cells or tissues can cause significant changes in target mRNA levels, suggesting that miRNAs can induce mRNA destabilization $[29,37]$. In eukaryotes, mRNA degradation can occur when there is a shortening of the poly(A) tail. As part of the RISC, Ago proteins 1, 3, and 4 are thought to repress translation by promoting poly(A) tail-mediated degradation [38]. One study demonstrated that miRNAmediated deadenylation of maternal mRNAs is necessary during zebrafish embryogenesis [37].

Further, miRNAs function in P-bodies by sequestering target transcripts for storage, decapping, deadenylation, and degradation [28]. Interestingly, P-bodies may also act as a temporary storage space for translationally repressed mRNAs. Since most P-body components are also found dispersed in the cytosol, it is likely that repression by these proteins is initiated in the cytosol, and the repressed mRNAs then aggregate to form the P-body. Stress granules are another type of body containing repressed mRNAs, and they accumulate in response to stress conditions or general inhibition of translation [39].

\section{Bone remodeling}

The skeleton is continuously remodeled throughout the lifetime of an individual, and this remodeling is a dynamic process by which bone resorption is coupled to bone formation, to replace damaged bone or to respond to metabolic needs [40]. To provide some context in which to appreciate the function of miRNAs in the skeleton, we will briefly consider the steps of bone remodeling and the signals important for osteoclast and osteoblast maturation.

Bone remodeling, or turnover, is mediated by the delicate balance of osteoblast and osteoclast numbers and activities (Figure 3). Osteoclasts resorb bone, whereas osteoblasts synthesize new bone. The release of cytokines at the site of remodeling recruits osteoclasts to the bone surface. The osteoclasts form a ruffled boarder that allows their tight adherence to the bone surface. The space between the osteoclast and the underlying bone becomes an isolated microenvironment into which the osteoclast's proton pump releases ions that generate an acidic environment, dissolving the mineralized component of the bone matrix. The organic matrix becomes exposed and is subsequently degraded by cathepsin $\mathrm{K}$ [41]. The reversal phase of bone remodeling begins with mononuclear cells preparing the bone surface for new osteoblasts and providing signals to recruit them. Early osteoblasts proliferate and secrete an extracellular matrix abundant in type I collagen. As the osteoblasts continue to differentiate, the matrix matures and is mineralized. Once the bone surface is restored, mature osteoblasts can undergo apoptosis or terminally differentiate into either bone surface lining cells or osteocytes, which are embedded in the calcified matrix and are responsive to mechanical stresses [42].

Differentiation of osteoclasts and osteoblasts from multipotent precursors is a critical component of bone turnover. Osteoclasts are derived from the monocyte/ macrophage lineage. Differentiation into osteoclasts is dependent on multiple extracellular signaling molecules, including macrophage colony-stimulating factor (MCSF), receptor activator for nuclear factor $\mathrm{\kappa B}$ ligand (RANKL), tumor necrosis factor, interferon gamma, and interleukins [41].

Osteoblasts are derived from mesenchymal stem cells (MSCs), which can differentiate into osteoblasts, adipocytes, chondrocytes, or myocytes, depending on the activation or inhibition of specific signaling pathways [43]. Some of the most important signaling molecules regulating osteoblastic differentiation include bone morphogenetic proteins (BMPs), transforming growth factor (TGF)- $\beta$, WNT, Hedgehog, parathyroid hormone, insulin-like growth factor-1, fibroblast growth factors, and Notch.

Misregulation of osteoclastic or osteoblastic differentiation could result in dysregulation of bone balance and 


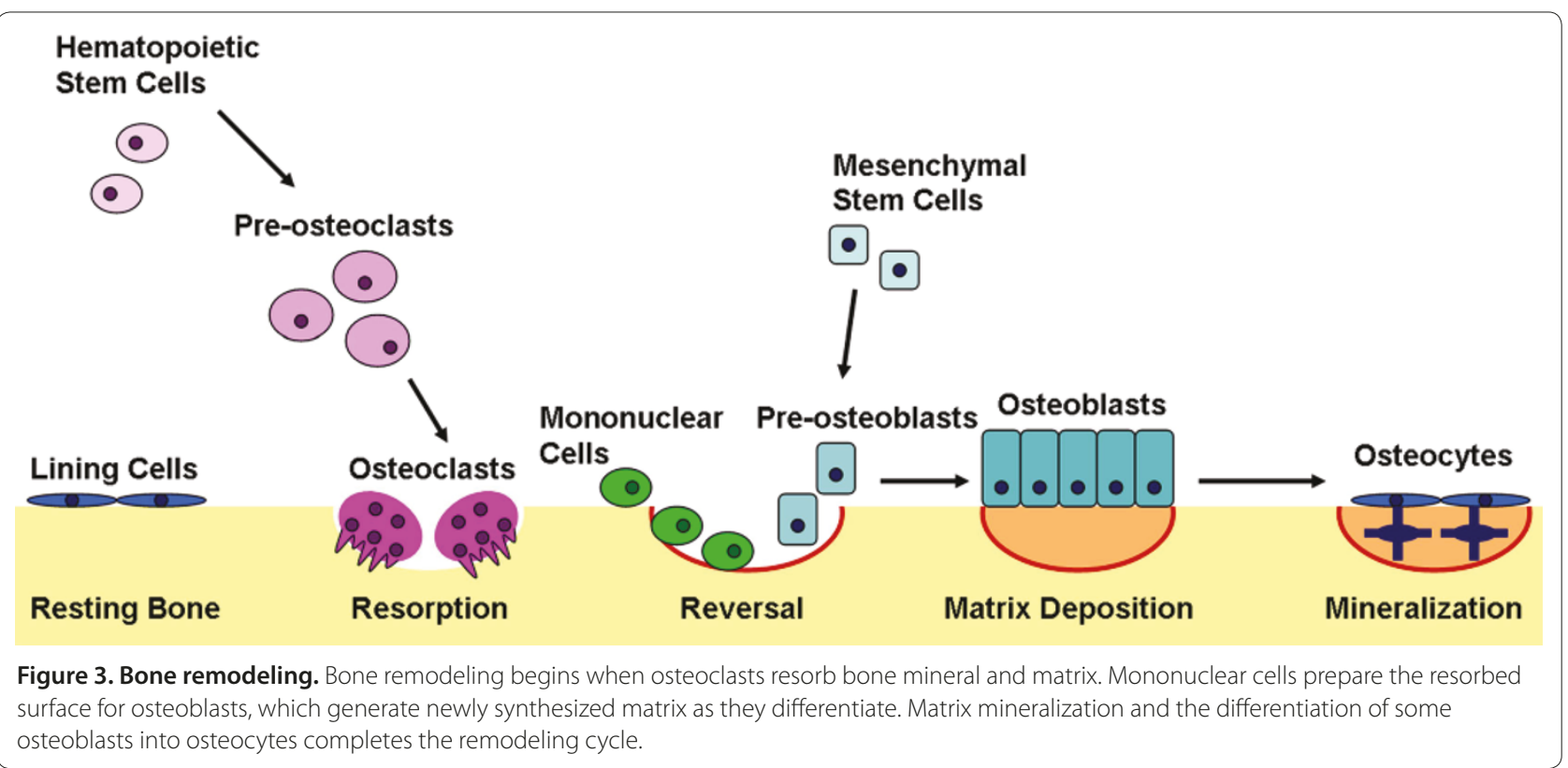

pathological consequences, including osteoporosis. miRNAs have been shown to regulate osteoblast and osteoclast differentiation and function. The following section will summarize the known roles of miRNAs in osteoblast and osteoclast biology.

\section{miRNAs in osteoblasts}

Cell type-specific deletion of Dicer in committed osteoprogenitors results in embryonic lethality at embryonic day (E)14.5 [44]. The mutant embryos display a deformed cartilaginous skeleton, and a lack of bone formation. This study used the rat 2.3-kb Colla1 promoter driven-Cre construct to delete the floxed Dicer alleles, and this Cre construct is transiently expressed during embryonic development, likely causing the embryonic lethality. These data reinforce the concept that Dicer-mediated miRNA processing is critical for osteogenesis.

Targeted deletion of Dicer in mature osteoblasts, using an osteocalcin-Cre construct, led initially to delayed perinatal bone formation, with a subsequent increase in postnatal bone acquisition [44]. In these mice, significant increases in cortical and trabecular bone volume were evident at 4 months of age, and persisted to 8 months. Long bone from mice lacking Dicer expression in mature osteoblasts had increased levels of mRNA for type I collagens, RANKL, and tartrate-resistant acid phosphatase (TRAP). Although data on osteoblast and osteoclast number were not reported, these results suggest increased bone remodeling in the mutant mice. In contrast, another group deleted Dicer in mature osteoblasts using a mouse 2.3-kb Coll promoter driven-Cre construct, and reported no effect on bone phenotype [45].
Comparing these two studies, it is likely that differences in the degree of Cre-mediated recombination and cell type specificity had an impact on the resulting mouse phenotypes. Nevertheless, these data suggest that Dicer activity is important for controlling both early and late bone cell differentiation programs.

In vitro knockdown of Dicer or Drosha in human MSCs inhibited osteogenic differentiation, confirming similar effects in human cells [46]. Indeed, since Dicer is important for the processing of many miRNAs, dramatic effects on cell differentiation with Dicer ablation are not unexpected. However, Dicer-independent mechanisms for miRNA maturation have recently been described [47]. It will be interesting to consider how these mechanisms may impact skeletal phenotype and to identify which miRNAs are regulated by these alternative pathways.

The BMP signaling pathway plays a prominent role in promoting osteoblast differentiation and bone formation [48]. Several studies have focused on miRNAs modulated by BMP signaling as a means to understand the role of miRNAs in osteoblasts. From these studies, it is clear that a panel of BMP-regulated miRNAs is important for the regulation of osteoblast differentiation. Since some miRNAs can be co-expressed and/or co-regulated, it is possible that families of miRNAs may promote one phenotype at the expense of another. This appears to be the case for miR-133 and miR-135, which are downregulated during BMP-2-induced osteoblastic differentiation of $\mathrm{C} 2 \mathrm{C} 12$ premyogenic cells, but are upregulated in these cells during myoblastic differentiation [49]. Over-expression of miR-133 or miR-135 blocked the BMP-mediated induction of osteoblastic markers, such 
as alkaline phosphatase (ALP), osteocalcin, and HOXA10. Further studies demonstrated that Runx2 is a target for miR-133, and Smad5 is a target for miR-135. Runx2 is a transcription factor essential for osteoblast differentiation, whereas Smad5 is an intracellular Runx2 coreceptor [50,51]. The concomitant down-regulation of these two miRNAs by BMP-2 likely plays an important role in the up-regulation of Runx2 and Smad5 during osteogenic differentiation.

Similarly, miR-206 is decreased in response to BMP-2 in $\mathrm{C} 2 \mathrm{C} 12$ cells and during differentiation of primary murine osteoblasts [52]. Over-expression of miR-206 inhibits ALP activity, and Connexin 43 (Cx43) was shown to be a target of miR-206. Cx43 is a gap junction protein necessary for osteoblast differentiation and function [53]. In vivo, miR-206 is highly expressed in muscle and perichondrial osteoblasts at E14.5, is moderately expressed in bone collar cells at E16.5, and is undetectable in bone at E18.5. Transgenic mice expressing miR-206 in mature osteoblasts display a low bone mass phenotype, particularly evident in the trabecular compartment. Bone formation rate was decreased in the transgenic mice, suggesting a defect in osteoblast function, whereas the osteoclast surface was unchanged. These data confirm miR-206 as a negative regulator of osteoblast function.

The sequences of mature miR-141 and miR-200a are very similar, and these two miRNAs are decreased in BMP-2-treated MC3T3-E1 osteoblastic cells. miR-141 and -200a appear to be negative regulators of osteoblast differentiation, since their over-expression inhibits this process. Dlx5 (Distal-less homeobox 5) is a master osteogenic transcription factor, and the 3' UTR for Dlx5 has a potential binding site for miR-141 or -200a [54]. In cells over expressing miR-141 or $-200 \mathrm{a}$, Dlx 5 protein levels were decreased. Since Dlx5 activates the transcription of osterix, a transcription factor crucial for osteoblast differentiation, it is possible that the BMP-2induced repression of miR-141 and -200a expression may indirectly augment the transcription of osterix, to promote osteoblastogenesis [55].

BMP-2 was also shown to decrease the expression of miR-208 [56]. Over-expression of miR-208 antagonized the BMP-2-mediated osteoblastic differentiation of MC3T3-E1 cells and primary mouse osteoblasts. The osteogenic transcription factor Ets1 was shown to be a target of miR-208. Ets1 stimulates the transcription of osteopontin and Runx2, and this was inhibited by miR-208 over-expression [56,57]. Thus, BMP-2 decreases miR-208 expression, allowing up-regulation of Ets1 and promoting osteoblastic differentiation.

In ST2 mouse mesenchymal cells, miR-125b expression is decreased after a 6-day treatment with BMP-4. miR$125 \mathrm{~b}$ has a negative effect on osteoblastic differentiation, as over-expression of miR-125b decreased ALP activity and knockdown of miR-125b increased ALP. Potential targets for miR-125b in osteoblasts have not been validated; however, miR-125b may play a role in regulating cell proliferation [58]. In contrast, miR-210 was found to be increased during BMP-4-induced osteoblastic differentiation of ST2 cells [59]. miR-210 plays a positive role in osteoblast differentiation. Transcripts for ALP and osterix were increased in ST2 cells over-expressing miR-210. Activin A receptor type 1B (AcvR1b) was identified as a target of miR-210. AcvR1b is essential for activin signaling, which may play a role in repressing osteoblastic differentiation [60].

Commitment of mesenchymal cells to a particular lineage depends on intracellular and extracellular cues to guide differentiation. miR-204 is induced during the adipogenic differentiation of murine C3H10T1/2 cells and human MSCs. Concomitantly, Runx2 is decreased. Runx2 is a target for miR-204. Over-expression of miR-204 negatively regulates Runx2 expression, inhibits osteoblast differentiation, and promotes adipocyte differentiation [61]. Runx2 can also be negatively regulated by some members of the miR-23a/27a/24-2 cluster in murine osteoblasts [62]. The cluster is up-regulated during differentiation of rat osteoblasts, but only miR-23 appears to directly target the Runx2 3' UTR.

During terminal osteoblastic differentiation of human adipocyte-derived stem cells, miR-26a expression is increased. Further, as miR-26a increases, SMAD1 levels decrease. SMAD1 was shown to be a target for miR-26a, and knockdown of miR-26a increased the expression of osteoblast maker genes, including those encoding COL1A1, osteopontin, and osteocalcin [63]. SMAD1 is a critical downstream mediator of BMP signaling, and increased expression of SMAD1 augments osteoblastogenesis.

miR-199a and -346 are up-regulated during osteoblastic or adipogenic differentiation of human MSCs [46]. These miRNAs negatively regulate leukemia inhibitory factor (LIF), which is a marker for human MSC multipotency, and is associated with the uncommitted state of embryonic and adult stem cells [64]. Indeed, expression of LIF is decreased as stem cell plasticity is decreased. The inhibition of LIF by miR-199a and -346 in human MSCs likely contributes to the induction of differentiation.

The miR-29 family is one of the best characterized miRNA families with regard to osteoblast function, and these miRNAs are important positive regulators of osteoblast differentiation. The expression of miR-29 family members is low during the early, matrix deposition phases of osteoblastogenesis. A low level of miR-29 expression is important at this time since miR-29 targets bone matrix RNAs, including COL1A1, COL3A1, and osteonectin $(O N) / S P A R C$ (secreted protein acidic and rich in cysteine) $[65,66]$. The co-regulation of osteonectin and fibrillar collagens is not unexpected, since 
osteonectin plays a critical role in regulating collagen fibril formation [67].

Later, the expression of miR-29 is increased as the matrix matures and the osteoblast achieves terminal maturation. This increase in miR-29 likely plays a role in the time-dependent suppression of collagen synthesis, which may be necessary to prevent fibrosis, and to allow for subsequent mineral deposition and proper fibril alignment, both of which are necessary for normal bone turnover [68,69]. Over-expression of miR-29 family members promotes osteoblastic differentiation, whereas knockdown of miR-29 decreases differentiation markers. It is interesting to note that other validated targets for miR-29, important in osteoblast function, include several proteins that are inhibitors of osteoblast differentiation, such as histone deacetylase (HDAC)4, TGF 33 , AcvR2A, CTNNBIP1 (catenin beta interacting protein I), and DUSP2 (dual specific phosphatase 2) [70].

It was recently reported that canonical Wnt signaling, a critical positive regulator of osteoblast differentiation, rapidly induces the expression of miR-29a and -29c [65]. Since activation of canonical Wnt signaling tends to increase during osteoblast differentiation, it is possible that Wnt signaling plays a role in the increased expression of miR-29 observed during osteoblast differentiation [71]. Further, miR-29a modulates canonical Wnt signaling in a positive feedback loop, to promote human osteoblast differentiation [72]. In human osteoblasts, transcription of miR-29a is induced by canonical Wnt signaling, and two T-cell factor/lymphoid enhancer factor (TCF/LEF) binding sites in the miR-29a promoter region are necessary for this induction. miR-29a was also found to target three inhibitors of Wnt signaling, Dkk1 (dikkopf-1), Kremen2 (kringle domain-containing transmembrane protein), and sFRP2 (secreted frizzled related protein 2). Thus, the induction of miR-29a transcription, in response to canonical Wnt signaling, results in decreased Dkk1, Kremen2, and sFRP2 levels, which potentiates Wnt signaling. This loop provides an additional mechanism by which miR-29 can promote human osteoblast differentiation, and a mechanism for fine tuning the expression of specific components in the Wnt signaling pathway [71,72].

A similar study demonstrated that miR-27, which is increased during osteoblast differentiation, positively regulates this process by targeting adenomatous polyposis coli (APC) [73]. In the absence of canonical Wnt signaling, APC is part of an inhibitor complex that binds $\beta$-catenin, preventing $\beta$-catenin translocation to the nucleus. This study suggests miR-27 promotes osteoblast differentiation by down-regulating APC, thus allowing for Wnt signaling. Indeed, over-expression of miR-27 increased ALP and osteocalcin, whereas its inhibition decreased these markers.
In the first study assessing miRNAs and osteoporosis in humans, an inactivating mutation in miR-2861 was found to be associated with decreased serum markers of osteoblast activity in a kindred of osteoporosis patients [74]. Interestingly, miR-2861 appears to be a bone-enriched miRNA. It is highly expressed in osteoblasts, with a lower level of expression in liver. Knockdown of miR-2861 in mice resulted in decreased bone volume, bone formation rate and osteoblast surface. Conversely, increased expression of this miRNA in vitro augmented osteoblast differentiation. miR-2861 was shown to target the protein coding region of HDAC5. HDAC5 mediates deacetylation of Runx2 and deacetylated Runx2 undergoes Smurf1mediated degradation [75]. Therefore, HDAC5 inhibition by miR-2861 likely increases the abundance of acetylated Runx2, allowing for augmentation of osteoblast differentiation. This key study demonstrates the importance of miRNA genes and their contribution to human disease phenotypes.

Transcribed in the same pri-miRNA as miR-2861 is another novel miRNA, miR-3960. These miRNAs likely work in concert, promoting osteoblastic differentiation by indirectly up-regulating Runx2 [76]. When miR-3960 is over-expressed, ALP, osteocalcin, and Runx2 are increased. Conversely, these differentiation markers are decreased when miR-3960 is inhibited. miR-3960 was found to directly target Hoxa2, a negative regulator of Runx2. Thus, the down-regulation of Hoxa2 by miR-3960 results in increased Runx2 expression. Further, Runx2 can bind the miR-3960 promoter, suggesting regulation of this miRNA cluster.

Overall, it is clear that miRNAs play an important role in osteoblast function and differentiation (summarized in Table 1). Future work, defining the function of particular miRNAs in osteoblast commitment and differentiation, could allow for the assembly of a panel of miRNAs that could be used as differentiation markers, similar to the panel of markers presently used to annotate the progression of differentiation, such as Runx2, ALP, osteocalcin, and osterix.

\section{miRNAs in osteoclasts}

Studies addressing the role of miRNAs in osteoclastogenesis are relatively limited. However, cell-type-specific deletion of Dicer at different stages in the osteoclast lineage highlight the general importance of miRNAs in osteoclast function. For example, deletion of Dicer in mature osteoclasts, using a cathepsin $\mathrm{K}$ promoter drivenCre transgene in mice bearing floxed Dicer alleles, resulted in increased bone mass in the trabecular compartment, due to a decrease in osteoclast number and surface [45]. Osteoclastogenesis in vitro was suppressed, suggesting a cell autonomous phenomenon. Interestingly, deletion of Dicer in mature osteoclasts also 
Table 1. Summary of microRNAs, their targets, expression, and effects on osteoblast differentiation

\begin{tabular}{|c|c|c|c|c|c|}
\hline miRNA & $\begin{array}{l}\text { Target } \\
\text { gene(s) }\end{array}$ & $\begin{array}{l}\text { Endogenous miRNA } \\
\text { expression }\end{array}$ & miRNA over-expression & miRNA inhibition & Reference \\
\hline $125 b$ & NR & $\begin{array}{l}\text { Decreased in BMP4-induced } \\
\text { osteoblastic differentiation of ST2 } \\
\text { cells }\end{array}$ & Inhibits ALP activity & Increases ALP activity & [58] \\
\hline 133 & Runx2 & $\begin{array}{l}\text { Decreased in BMP2-induced } \\
\text { osteoblast differentiation of } \mathrm{C} 2 \mathrm{C} 12 \\
\text { cells }\end{array}$ & $\begin{array}{l}\text { Decreases ALP and osteocalcin } \\
\text { mRNA }\end{array}$ & NR & [49] \\
\hline 135 & Smad5 & & & & \\
\hline $\begin{array}{l}141 \\
200 a\end{array}$ & D/x5 & $\begin{array}{l}\text { Repressed by BMP in MC3T3-E1 } \\
\text { cells }\end{array}$ & Inhibits ALP activity & Increases ALP activity & [54] \\
\hline $\begin{array}{l}199 a, \\
346\end{array}$ & LIF & $\begin{array}{l}\text { Increased during osteoblast } \\
\text { differentiation of hMSCs }\end{array}$ & NR & NR & {$[46]$} \\
\hline 204 & Runx2 & $\begin{array}{l}\text { Increased in } \mathrm{C} 3 \mathrm{H} 10 \mathrm{~T} 1 / 2 \text { cells and } \\
\text { hMSCs during adipogenesis }\end{array}$ & $\begin{array}{l}\text { Enhances adipogenesis (increases } \\
\text { oil red O staining, and AP2, } \\
\text { adipsin, and PPARY mRNA); inhibits } \\
\text { osteoblastogenesis (decreases ALP } \\
\text { activity, and ALP, osteopontin, and } \\
\text { osteocalcin mRNA) }\end{array}$ & $\begin{array}{l}\text { Enhances osteoblastogenesis } \\
\text { (increases ALP activity, and ALP, } \\
\text { osteopontin, and osteocalcin } \\
\text { mRNA); inhibits adipogenesis } \\
\text { (decreases oil red O staining, and } \\
\text { AP2, adipsin, and PPARY mRNA) }\end{array}$ & [61] \\
\hline 206 & Connexin 43 & $\begin{array}{l}\text { Decreased in BMP2-induced } \\
\text { osteoblastic differentiation of } \\
\mathrm{C} 2 \mathrm{C} 12 \text { cells; deceased during } \\
\text { osteoblastic differentiation of } \\
\text { primary mouse osteoblasts }\end{array}$ & $\begin{array}{l}\text { Causes osteopenia in vivo; decreases } \\
\text { osteocalcin and Runx } 2 \text { mRNA, and } \\
\text { ALP activity; increases myogenic } \\
\text { markers (MyoD, Myf5) }\end{array}$ & Increases ALP activity & [52] \\
\hline 208 & Ets1 & $\begin{array}{l}\text { Repressed by BMP treatment in } \\
\text { MC3T3-E1 cells }\end{array}$ & $\begin{array}{l}\text { Decreases ALP activity, Alizarin red } \\
\text { staining, and osteopontin protein }\end{array}$ & No effect & {$[56]$} \\
\hline 210 & $A c \vee R 1 b$ & $\begin{array}{l}\text { Increased in BMP4-induced } \\
\text { osteoblastic differentiation of ST2 } \\
\text { cells }\end{array}$ & $\begin{array}{l}\text { Increases ALP, osteocalcin, and } \\
\text { osterix mRNA, and ALP activity }\end{array}$ & Decreases osteocalcin mRNA & [59] \\
\hline $\begin{array}{c}23 a / 27 a / \\
24-2\end{array}$ & Runx2, SATB2 & $\begin{array}{l}\text { Increased during osteoblastic } \\
\text { differentiation of rat primary } \\
\text { osteoblasts }\end{array}$ & $\begin{array}{l}\text { Decreases ALP activity and mRNA, } \\
\text { vonKossa staining, Runx2, osterix, } \\
\text { and osteocalcin mRNA }\end{array}$ & NR & [62] \\
\hline $26 a$ & SMAD1 & $\begin{array}{l}\text { Increased during terminal } \\
\text { osteoblastic differentiation in } \\
\text { hADSCs }\end{array}$ & NR & $\begin{array}{l}\text { Increases ALP, osteopontin, and } \\
\text { osteocalcin mRNA }\end{array}$ & [63] \\
\hline 27 & $A P C$ & $\begin{array}{l}\text { Increased during osteoblastic } \\
\text { differentiation of hFOB } 1.19 \text { cells }\end{array}$ & $\begin{array}{l}\text { Increases ALP and osteocalcin } \\
\text { mRNA; augments Wnt signaling }\end{array}$ & $\begin{array}{l}\text { Decreases ALP and osteocalcin } \\
\text { mRNA }\end{array}$ & [73] \\
\hline 2861 & HDAC5 & $\begin{array}{l}\text { Increased in BMP2-induced } \\
\text { osteoblastic differentiation of ST2 } \\
\text { cells; enriched in human bone }\end{array}$ & $\begin{array}{l}\text { Augments BMP-induced increase in } \\
\text { osteocalcin mRNA }\end{array}$ & $\begin{array}{l}\text { Decreases bone volume and BFR } \\
\text { in vivo; patients homozygous for } \\
\text { miR-2861 mutation have very low } \\
\text { bone mass }\end{array}$ & [74] \\
\hline $\begin{array}{l}29 a \\
29 c\end{array}$ & $\begin{array}{l}\text { COL1A1, COL3A1, } \\
\text { Osteonectin/ } \\
\text { SPARC, Kremen2, } \\
\text { Dkk1, Sfrp2 }\end{array}$ & $\begin{array}{l}\text { Increased during osteoblastic } \\
\text { differentiation in MC3T3-E1 cells, } \\
\text { primary osteoblasts (human and } \\
\text { mouse), and hFOB1.19 cells }\end{array}$ & $\begin{array}{l}\text { Increases osteocalcin mRNA; } \\
\text { potentiates Wnt signaling }\end{array}$ & $\begin{array}{l}\text { Inhibits ALP and osteocalcin } \\
\text { mRNA, and ALP activity; blunts Wnt } \\
\text { signaling }\end{array}$ & $\begin{array}{c}{[60,68,} \\
72]\end{array}$ \\
\hline $29 b$ & $\begin{array}{l}\text { COL1A1, HDAC4, } \\
\text { DUSP2, TGF } 33, \\
\text { ACVR2a, CTNNBIP1 }\end{array}$ & $\begin{array}{l}\text { Increased during osteoblastic } \\
\text { differentiation in MC3T3-E1 cells }\end{array}$ & Increases ALP mRNA and ALP activity & NR & [70] \\
\hline 3960 & Hoxa2 & $\begin{array}{l}\text { Increased in response to BMP-2 in } \\
\text { mouse primary osteoblasts }\end{array}$ & $\begin{array}{l}\text { Increases ALP, osteocalcin, and Runx } 2 \\
\text { mRNA }\end{array}$ & $\begin{array}{l}\text { Decreases ALP, osteocalcin, and } \\
\text { Runx } 2 \text { mRNA }\end{array}$ & {$[76]$} \\
\hline
\end{tabular}

ALP, alkaline phosphatase; BFR, bone formation rate; BMP, bone morphogenetic protein; hADSC, human adipocyte derived stem cell; hMSC, human mesenchymal stem cell; miRNA, microRNA; NR, not reported; PPAR, peroxisome proliferator-activated receptor.

resulted in decreased bone formation rate, indicating an overall decrease in bone remodeling. These authors reported that miRNA expression microarray analysis showed little change in the miRNA profile in bone marrow macrophages (BMMs) treated for 24 hours with MCSF/RANKL to induce osteoclastogenesis. In this study, expression of miR-302c was stimulated to the greatest extent (approximately 1.8-fold), and this miRNA has been implicated in stem cell pluripotency [77].

Similar results were obtained with Dicer knockdown in osteoclast precursors and mature osteoclasts [78]. Expression of a $C D 11 \mathrm{~b}$ promoter driven-Cre transgene in mice bearing floxed Dicer alleles resulted in increased trabecular bone volume. The mice had decreased 
osteoclast numbers and decreased bone resorption, without alterations in osteoblast parameters. In vitro, small interfering RNA-mediated knockdown (approximately 60\% knockdown) of DGCR8, Ago2, or Dicer1 in mouse BMMs antagonized the RANKLinduced stimulation of osteoclast differentiation markers, including c-fos, PU.1, and NFATc1 [78].

This group also studied the function of miR-223 in osteoclastogenesis, since it is expressed in osteoclast precursors. Knockdown of miR-223 decreased the RANKL-induced formation of osteoclast-like cells in mouse RAW264.7 cells. However, over-expression of miR-223 also had a similar effect. These data suggest that appropriate levels of miR-223 expression are important for normal osteoclastogenesis. Interestingly, knockdown of miR-223 resulted in an increase in NFI-A, a suppressor of osteoclastogenesis. Bioinformatics suggests that the 3' UTR for NFI-A may have a potential miR-223 binding site. Further, two PU.1 binding sites are present in the miR-223 promoter region [79]. The authors hypothesize that in osteoclast precursors, PU.1, induced by MCSF, may stimulate transcription of miR-223 and RANK. Mature miR-223 then likely targets NFI-A to increase expression of MCSF receptor, which is critical for osteoclast differentiation, function, and survival [80].

Another group demonstrated increased association of cFos and PU.1 with the miR-21 promoter during osteoclast differentiation of mouse BMMs [81]. In BMMs transduced with a miR-21-antisense lentivirus, expression of PDCD4 (programmed cell death 4), a repressor of c-Fos, was increased. This effect correlated with decreased osteoclast differentiation markers, including c-Fos, cathepsin $\mathrm{K}$, NFATc1, and TRAP staining, compared to controls.

In contrast, miR-155 acts as a molecular switch in monocytic cells to repress osteoclast formation and promote the macrophage fate [82]. miR-155 is downregulated in osteoclasts and up-regulated in macrophages. Over-expression of miR-155 in RAW 264.7 monocytes blocked the formation of multinucleated osteoclasts, suppressed TRAP staining, blocked boneresorbing activity, and increased macrophage differentiation. Conversely, knockdown of miR-155 caused an increase in osteoclasts and decrease in macrophages. The authors found that microphthalmia-associated transcription factor is a direct target of miR-155, and that it activates transcription of GPNMB (glycoprotein NMB, osteoactivin), a transmembrane protein critical for osteoclast differentiation. Therefore, down-regulation of miR-155 is important for osteoclastogenesis.

As with osteoblasts, there is likely a panel of miRNAs important for osteoclast function and differentiation. More research will reveal these miRNAs and how they interact with signaling molecules to control osteoclast phenotypes.

\section{Conclusion}

These studies represent the first steps in demonstrating the importance of miRNAs in the control of osteoblast and osteoclast differentiation and function, and their role in bone turnover. An in-depth understanding of the roles of these regulatory RNAs in the skeleton will be critical for the development of new therapeutics aimed at treating bone loss and perhaps facilitating fracture repair. Although current therapies can be effective at preventing bone loss, there are patients who are refractory to treatment. The inhibition or over-expression of certain miRNAs in a tissue-specific manner has shown some promise in the treatment of tumors in animal models, and miRNA-based therapeutics have recently gone into clinical trials [83]. There are two obvious benefits of miRNA-based therapeutics. miRNA oligonucleotide inhibitors or mimics can be targeted to specific tissues using relatively non-toxic delivery vehicles. In addition, these molecules can be relatively cost-effective compared to current peptide-based therapies. Much more work needs to be done to determine which miRNAs are important in bone, and to define their roles in bone remodeling, fracture repair, and bone-related diseases.

\section{Abbreviations}

AcvR, activin A receptor; Ago, Argonaute; ALP, alkaline phosphatase; APC, adenomatous polyposis coli; BMM, bone marrow macrophage; BMP, bone morphogenetic protein; bp, base pair; DGCR8, DiGeorge syndrome critical region gene 8 ; $\mathrm{E}$, embryonic day; $H D A C$, histone deacetylase; LIF, leukemia inhibitory factor; MCSF, macrophage colony-stimulating factor; miRNA, microRNA; MSC, mesenchymal stem cell; P-body, processing body; pre-miRNA, precursor miRNA; pri-miRNA, primary miRNA; RANKL, receptor activator for nuclear factor kappa B ligand; RISC, RNA-induced silencing complex; TGF, transforming growth factor; TRAP, tartrate-resistant acid phosphatase; TRBP, Dicer-TAR RNA binding protein; UTR, untranslated region.

\section{Competing interests}

The authors declare that they have no competing interests.

\section{Acknowledgements}

This work was funded by NIH-NIAMS (AR44877 to AMD).

\section{Author details}

'Current address: Cell Biology Department, Room S7-318, University of Massachusetts Medical School, 55 Lake Avenue North, Worcester, MA 01655, USA. ${ }^{2}$ Center for Molecular Medicine, University of Connecticut Health Center, 263 Farmingtion Ave, Farmington, CT 06030, USA.

\section{Published: 27 May 2011}

\section{References}

1. Keene JD: RNA regulons: coordination of post-transcriptional events. Nat Rev Genet 2007, 8:533-543.

2. Ambros V: The functions of animal microRNAs. Nature 2004, 431:350-355

3. Bartel DP: MicroRNAs: genomics, biogenesis, mechanism, and function. Cell 2004, 116:281-297.

4. Lee RC, Feinbaum RL, Ambros V: The C. elegans heterochroic gene lin-4 encodes small RNAs with antisense complementarity to lin-14. Cell 1993, 75:843-854.

5. Wightman B, Ha I, Ruvkun G: Posttranscriptional regulation of the heterochroic gene lin-14 by lin- 4 mediates temporal pattern formation in C. elegans. Cell 1993, 75:855-862.

6. Lee Y, Kim M, Han J, Yeom KH, Lee S, Baek SH, Kim VN: MicroRNA genes are transcribed by RNA polymerase II. EMBO J 2004, 23:4051-4060. 
7. Borchert GM, Lanier W, Davidson BL: RNA polymerase III transcribes human microRNAs. Nat Struct Mol Biol 2006, 13:1097-1101.

8. Cai X, Hagedorn CH, Cullen BR: Human microRNAs are processed from capped, polyadenylated transcripts that can also function as mRNAs. RNA 2004, 10:1957-1966.

9. Han J, Lee Y, Yeom KH, Kim YK, Jin H, Kim VN: The Drosha-DGCR8 complex in primary microRNA processing. Genes Dev 2004, 18:3016-3027.

10. Han J, Lee Y, Yeom KH, Nam JW, Heo I, Rhee JK, Sohn SY, Cho Y, Zhang BT, Kim VN: Molecular basis for the recognition of primary microRNAs by the Drosha-DGCR8 complex. Cell 2006, 125:887-901.

11. Lund E, Guttinger S, Calado A, Dahlberg JE, Kutay U: Nuclear export of microRNA precursors. Science 2004, 303:95-98

12. Berezikov E, Chung WJ, Willis J, Cuppen E, Lai EC: Mammalian mirtron genes. Mol Cell 2007, 28:328-336.

13. Chendrimada TP, Gregory RI, Kumaraswamy E, Norman J, Cooch N, Nishikura K, Shiekhattar R: TRBP recruits the Dicer complex to Ago2 for microRNA processing and gene silencing. Nature 2005, 436:740-744

14. Kawamata T, Seitz H, Tomari Y: Structural determinants of miRNAs for RISC loading and slicer-independent unwinding. Nat Struct Mol Biol 2009, 16:953-960.

15. Zhang $X$, Zeng $Y$ : The terminal loop region controls microRNA processing by Drosha and Dicer. Nucleic Acids Res 2010, 38:7689-7697.

16. Landthaler M, Gaidatzis D, Rothballer A, Chen PY, Soll SJ, Dinic L, Ojo T, Hafner M, Zavolan M, Tuschl T: Molecular characterization of human Argonautecontaining ribonucleoprotein complexes and their bound target mRNAs. RNA 2008, 14:2580-2596.

17. Takeda A, Iwasaki S, Watanabe T, Utsumi M, Watanabe Y: The mechanism selecting the guide strand from small RNA duplexes is different among argonaute proteins. Plant Cell Physiol 2008, 49:493-500.

18. Ro S, Park C, Young D, Sanders KM, Yan W: Tissue-dependent paired expression of miRNAs. Nucleic Acids Res 2007. 35:5944-5953.

19. Kai ZS, Pasquinelli AE: MicroRNA assassins: factors that regulate the disappearance of miRNAs. Nat Struct Mol Biol 2010, 17:5-10.

20. Bail S, Swerdel M, Liu H, Jiao X, Goff LA, Hart RP, Kiledjian M: Differential regulation of microRNA stability. RNA 2010, 16:1032-1039.

21. Lytle JR, Yario TA, Steitz JA: Target mRNAs are repressed as efficiently by microRNA-binding sites in the $5^{\prime}$ UTR as in the $3^{\prime}$ UTR. Proc Natl Acad Sci USA 2007, 104:9667-9672

22. Duursma AM, Kedde M, Schrier M, le Sage C, Agami R: miR-148 targets human DNMT3b protein coding region. RNA 2008, 14:872-877.

23. Gu S, Jin L, Zhang F, Sarnow P, Kay MA: Biological basis for restriction of microRNA targets to the $3^{\prime}$ untranslated region in mammalian mRNAs. Nat Struct Mol Biol 2009, 16:144-150

24. Lewis $B$, Burge $C B$, Bartel DP: Conserved seed pairing, often flanked by adenosines, indicates that thousands of human genes are microRNA targets. Cell 2005, 120:15-20.

25. Brenneke J, Stark A, Russell RB, Cohen SM: Principles of microRNA-target recognition. PLoS Biol 2005, 3:e85

26. Long D, Lee R, Williams $P$, Chang $C Y$, Ambros V, Ding Y: Potent effect of target structure on microRNA function. Nat Struct Mol Biol 2007, 14:287-294.

27. Saetrom P. Heale BS, Snove O, Aagaard L, Alluin J, Rossi J J: Distance constraints between microRNA target sites dictate efficacy and cooperativity. Nucleic Acids Res 2007, 35:2333-2342

28. Liu J, Valencia-Sanchez MA, Hannon GJ, Parker R: MicroRNA-dependent localization of targeted mRNAs to mammalian P-bodies. Nat Cell Biol 2005 7:719-723.

29. Eulalio A, Behm-Ansmant I, Izaurralde E: P bodies: at the crossroads of the post-transcriptional pathways. Nat Rev Mol Cell Biol 2007, 8:9-22.

30. Valencia-Sanchez MA, Liu J, Hannon GJ, Parker R: Control of translation and mRNA degradation by miRNAs and siRNAs. Genes Dev 2006, 20:515-524.

31. Merrick WC: Cap-dependent and cap-independent translation in eukaryotic systems. Gene 2004, 332:1-11.

32. Mathonnet G, Fabian MR, Svitkin YV, Parsyan A, Huck L, Murata T, Biffo S, MerrickWC, Darzynkiewicz E, Pillai RS, Filipowicz W, Duchaine TF, Sonenberg $\mathrm{N}$ : MicroRNA inhibition of translation initiation in vitro by targeting the cap-binding complex elF4F. Science 2007, 317:1764-1767.

33. Pillai RS, Bhattacharyya SN, Artus CG, Zoller T, Cougot N, Basyuk E, Bertrand E, Filipowicz W: Inhibition of translational initiation by Let-7 MicroRNA in human cells. Science 2005, 309:1573-1576.

34. Kiriakidou M, Tan GS, Lamprinaki S, De Plannell-Saquer M, Nelson PT, Mourelatos Z: An mRNA m7G cap binding-like motif within human Ago2 represses translation. Cell 2007, 129:1141-1151.

35. Olsen PH, Ambros V: The lin-4 regulatory RNA controls developmental timing in Caenorhabditis elegans by blocking LIN-14 protein synthesis after the initiation of translation. Dev Biol 1999, 216:671-680.

36. Petersen CP, Bordeleau ME, Pelletier J, Sharp PA: Short RNAs repress translation after initiation in mammalian cells. Mol Cell 2006, 21:533-542.

37. Giraldez AJ, Mishima Y, Rihel J, Grocock RJ, Van Dongen S, Inoue K, Enright AJ, Schier AF: Zebrafish MiR-430 promotes deadenylation and clearance of maternal mRNAs. Science 2006, 312:75-79.

38. Fabian MR, Mathonnet G, Sundermeier T, Mathys H, Zipprich JT, Svitkin YV, Rivas F, Jinek M, Wohlschlegel J, Doudna JA, Chen CY, Shyu AB, Yates Jr 3rd, Hannon GJ, Filipowicz W, Duchaine TF, Sonenberg N: Mammalian miRNA RISC recruits CAF1 and PABP to affect PABP-dependent deadenylation. Mol Cell 2009, 35:868-880.

39. Bhattacharyya SN, Habermacher R, Matrine U, Closs EL, Filipowicz W: Stressinduced reversal of microRNA repression and mRNA P-body localization in human cells. Cold Spring Harb Symp Quant Biol 2006, 71:513-521.

40. Raisz LG: Physiology and pathophysiology of bone remodeling. Clin Chem 1999, 45:1353-1358.

41. Ross FP: Osteoclast biology and bone resorption. In Primer on the Metabolic Bone Diseases and Disorders of Mineral Metabolism. 7th edition. Edited by Rosen CJ, Compston J, Lian JB. Washington, DC: American Society for Bone and Mineral Research; 2008:16-21.

42. Bonewald L: Osteocytes. In Primer on the Metabolic Bone Diseases and Disorders of Mineral Metabolism. 7th edition. Edited by Rosen CJ, Compston JE, Lian JB. Washington, DC: American Society of Bone and Mineral Research; 2008:22-26.

43. Krause C, de Gorter DJJ, Karperien M, ten Dijke P: Signal transduction cascades controlling osteoblast differentiation. In Primer on the Metabolic Bone Diseases and Disorders of Mineral Metabolism. 7th edition. Edited by Rosen CJ, Compston J, Lian JB. Washington, DC: American Society for Bone and Mineral Research; 2008:10-16.

44. Gaur T, Hussain S, Mudhasani R, Parulkar I, Colby JL, Frederick D, Kream BE, van Wijnen AJ, Stein JL, Stein GS, Jones SN, Lian JB: Dicer inactivation in osteoprogenitor cells compromises fetal survival and bone formation, while excision in differentiated osteoblasts increases bone mass in the adult mouse. Dev Biol 2010, 340:10-21

45. Mizoguchi F, Izu Y, Hayata T, Hemmi H, Nakashima K, Nakamura T, Kato S, Miyasaka N, Ezura Y, Noda, M: Osteoclast-specific Dicer gene deficiency suppresses osteoclastic bone resorption. J Cell Biochem 2010, 109:866-875.

46. Oskowitz AZ, Lu J, Penfornis P, Ylostalo J, McBride J, Flemington EK, Prockop DJ, Pochampally R: Human multipotent stromal cells from bone marrow and microRNA: regulation of differentiation and leukemia inhibitory factor expression. Proc Natl Acad SciU S A 2008, 105:18372-18377.

47. Cheloufi S, Dos Santos CO, Chong MM, Hannon GJ: A dicer-independent miRNA biogenesis pathway that requires Ago catalysis. Nature 2010, 465:584-589.

48. LeBoy P: Regulating bone growth and development with bone morphogenetic proteins. Ann N Y Acad Sci 2006, 1068:14-18.

49. Li Z, Hassan MQ, Volinia S, van Wijnen AJ, Stein JL, Croce CM, Lian JB, Stein GS A microRNA signature for a BMP2-induced osteoblast lineage commitment program. Proc Natl Acad Sci U S A 2008, 105:13906-13911.

50. Lee KS, Kim HJ, Li OL, Chi XZ, Ueta C, Komori T, Wozney JM, Kim EG, Choi JY, Ryoo HM, Bae SC: Runx2 is a common target of transformation growth factor beta 1 and bone morphogenetic protein 2 , and cooperation between Runx 2 and Smad5 induces osteoblast-specific gene expression in the pluripotent mesenchymal precursor cell line $\mathrm{C} 2 \mathrm{C} 12$. Mol Cell Biol 2000, 20:8783-8792.

51. Javed A, Bae JS, Afzal F, Gutierrez S, Pratap J, Zaidi SK, Lou Y, van Wijnen AJ, Stein JL, Stein GS, Lian, JB: Structural coupling of Smad and Runx2 for execution of the BMP2 osteogenic signal. J Biol Chem 2008, 283:8412-8422.

52. Inose $\mathrm{H}$, Ochi H, Kimura A, Fujita K, Xu R, Sato S, I wasaki M, Sunamura S, Takeuchi Y, Fukumoto S, Saito K, Nakamura T, Siomi H, Ito H, Arai Y, Shinomiya $\mathrm{KL}$, Takeda S: A microRNA regulatory mechanism of osteoblast differentiation. Proc Natl Acad Sci U S A 2009, 106:20794-20799.

53. Lecanda F, Warlow PM, Sheikh S, Furlan F, Steinberg TH, Civitelli R: Connexin43 deficiency causes delayed ossification, craniofacial abnormalities, and osteoblast dysfunction. J Cell Bio/ 2000, 151:931-944.

54. Itoh T, Nozawa Y, Akao Y: MicroRNA-141 and -200a are involved in bone morphogenetic protein-2-induced mouse pre-osteoblast differentiation by targeting distal-less homeobox 5. J Biol Chem 2009, 284:19272-19279. 
55. Ulsamer A, Ortuno MJ, Ruiz S, Susperregui AR, Osses N, Rosa JL, Ventura F: BMP-2 induces Osterix expression through up-regulation of DIx5 and its phosphorylation by p38. J Biol Chem 2008, 283:3816-3826.

56. Itoh T, Takeda S, Akao Y: MicroRNA-208 modulates BMP-2 stimulated mouse preosteoblast differentiation by directly targeting $\mathrm{V}$-ets erythroblastosis virus E26 oncogene homolog 1. J Biol Chem 2010, 285:27745-27752.

57. Raouf A, Seth A: Ets transcription factors and targets in osteogenesis. Oncogene 2000, 19:6455-6463.

58. Mizuno Y, Yagi K, Tokuzawa Y, Kanesaki-Yatsuka Y, Suda T, Katagiri T, Fukuda T, Maruyama M, Okuda A, Amemiua T, Kondoh Y, Tashiro H, Okazaki Y: miR-125b inhibits osteoblastic differentiation by down-regulation of cell proliferation. Biochem Biophys Res Commun 2008, 368:267-272.

59. Mizuno Y, Tokuzawa Y, Ninomiya Y, Yagi K, Yatsuka-Kanesaki Y, Suda T, Fukuda T, Katagiri T, Kondoh Y, Amemiya T, Tashiro H, Okazaki Y: miR-210 promotes osteoblastic differentiation through inhibition of AcvR1b. FEBS Lett 2009, 583:2263-2268.

60. Miyazono K, Maeda S, Imamura T: BMP receptor signaling: transcriptional targets, regulation of signals, and signaling cross-talk. Cytokine Growth Factor Res 2005, 16:251-263.

61. Huang J, Zhao L, Xing L, Chen D: MicroRNA-204 regulates Runx2 protein expression and mesenchymal progenitor cell differentiation. Stem Cells 2010, 28:357-364

62. Hassan MQ, Gordon JA, Beloti MM, Croce CM, van Wijnen AJ, Stein JL, Stein GS, Lian JB: A network connecting Runx2, SATB2, and the miR23a 27a 24-2 cluster regulates the osteoblast differentiation program. Proc Natl Acad Sci U S A 2010, 107:19879-19884

63. Luzi E, Marini F, Sala SC, Tognarini I, Galli G, Brandi ML: Osteogenic differentiation of human adipose tissue-derived stem cells is modulated by the miR-26a targeting of the SMAD1 transcription factor. J Bone Miner Res 2008, 23:287-295.

64. Williams RL, Hilton DJ, Pease S, Willson TA, Stewart CL, Gearing DP, Wagner EF, Metcalf D, Nicola NA, Gough NM: Myeloid leukaemia inhibitory factor maintains the developmental potential of embryonic stem cells. Nature 1988, 336:684-687.

65. Kapinas K, Kessler CB, Delany AM: miR-29 suppression of osteonectin in osteoblasts: regulation during differentiation and by canonical Wnt signaling. J Cell Biochem 2009, 108:216-224.

66. Sengupta S, den Boon JA, Chen IH, Newton MA, Stanhope SA, Cheng YJ Chen CJ, Hildesheim A, Sugden B, Ahlquist P: MicroRNA 29c is downregulated in nasopharyngeal carcinomas, up-regulated mRNAs encoding extracellular matrix proteins. Proc Natl Acad Sci U S A 2008, 105:5874-5878.

67. Bradshaw AD: The role of SPARC in extracellular matrix assembly. J Cell Commun Signal 2009, 3:239-246.

68. Van Rooij E, Sutherland LB, Thatcher JE, DiMaio JM, Naseem RH, Marshall WS, Hill JA, Olson EN: Dysregulation of microRNAs after myocardial infarction reveals a role of miR-29 in cardiac fibrosis. Proc Natl Acad Sci U S A 2008, 105:13027-13032.
69. Golub EE: Role of matrix vesicles in biomineralization. Biochim Biophys Acta 2009, 1790:1592-1598.

70. Li Z, Hassan MQ, Jafferji M, Aqeilan Rl, Garzon R, Croce CM, van Wijnen AJ, Stein JL, Stein GS, Lian JB: Biological functions of miR-29b contribute to positive regulation of osteoblast differentiation. J Biol Chem 2009, 284:15676-15684.

71. Hartmann C: A Wnt canon orchestrating osteoblastogenesis. Trends Cell Biol 2006, 16:151-158.

72. Kapinas K, Kessler CB, Ricks T, Gronowicz G, Delany AM: miR-29 modulates Wnt signaling in human osteoblasts through a positive feedback loop. J Biol Chem 2010, 285:25221-25231.

73. Wang T, Xu Z: miR-27 promotes osteoblast differentiation by modulating Wnt signaling. Biochem Biophys Res Commun 2010, 402:186-189.

74. Li H, Xie H, Liu W, Hu R, Huang B, Tan YF, Xu K, Sheng ZF, Zhou HD, Wu XP, Luo $\mathrm{XH}$ : A novel microRNA targeting HDAC5 regulates osteoblast differentiation in mice and contributes to primary osteoporosis in humans. J Clin Invest 2009, 119:3666-3677.

75. Jeon EJ, Lee KY, Choi NS, Lee MH, Kim HN, Jin YH, Ryoo HM, Choi JY, Yoshida M, Nishino N, Oh BC, Lee KS, Lee YH, Bae SC: Bone morphogenetic protein-2 stimulates Runx2 acetylation. J Biol Chem 2006, 281:16502-16511.

76. Hu R, Liu W, Li H, Yang L, Chen C, Xia ZY, Guo LJ, Xie H, Zhou HD, Wu XP, Luo XH: A RUNX2/MIR-3960/MIR-2861 regulatory feedback loop during mouse osteoblast differentiation. J Biol Chem 2011, 286:12328-12339.

77. Barroso-del Jesus A, Lucena-Aguilar G, Menendez, P: The miR-302-367 cluster as a potential stemness regulator in ESCs. Cell Cycle 2009, 8:394-398

78. Sugatani T, Hruska KA: Impaired micro-RNA pathways diminish osteoclast differentiation and function. J Bio/ Chem 2009, 284:4667-4678.

79. Fukao T, Fukuda Y, Kiga K, Sharif J, Hino K, Enomoto Y, Kawamura A, Nakamura K, Takeuchi T, Tanabe M: An evolutionarily conserved mechanism for microRNA-223 expression revealed by microRNA gene profiling. Cell 2007 129:617-631.

80. Karsenty G, Wagner EF: Reaching a genetic and molecular understanding of skeletal development. Dev Cell 2002, 2:389-406.

81. Sugatani T, Vacher J, Hruska KA: A microRNA expression signature of osteoclastogenesis. Blood 2011, 117:3648-3657.

82. Mann M, Barad O, Agami R, Geiger B, Hornstein E: miRNA-based mechanism for the commitment of multipotent progenitors to a single cellular fate. Proc Natl Acad Sci U S A 2010, 107:15804-15809.

83. Tiemann K, Rossi JJ: RNAi-based therapeutics-current status, challenges and prospects. EMBO Mol Med 2009, 1:142-151.

doi:10.1186/ar3325

Cite this article as: Kapinas K, Delany AM: MicroRNA biogenesis and regulation of bone remodeling. Arthritis Research \& Therapy 2011, 13:220. 